\title{
Evaluation of Ovarian Masses by Color Doppler Imaging and Histopathological Correlation
}

\author{
Subrat Prasad ${ }^{1}$, Mihir Kumar Jha ${ }^{2}$, Shalini Sahu ${ }^{3}$, Ichchhit Bharat ${ }^{4}$, Chandni Sehgal $^{5}$ \\ ${ }^{1}$ Associate Professor, Department of Radiodiagnosis, Mata Gujri Memorial Medical College \& LSK Hospital, Purabbali, \\ Dinajpur Road, Kishanganj, Bihar; ${ }^{2}$ Associate Professor, Department of Radiodiagnosis, Shri Ramkrishna Institute of Medical \\ Sciences and Sanaka Hospital, Malandighi, Kanksha, Durgapur, West Bengal; ${ }^{3}$ Associate Professor, Department of Obstetrics \\ \& Gynaecology, Mata Gujri Memorial Medical College \& LSK Hospital, Purabbali, Dinajpur Road, Kishanganj, Bihar, India; \\ ${ }^{4}$ Senior Resident, Department of Dermatology, Mata Gujri Memorial Medical College \& LSK Hospital, Purabbali, Dinajpur \\ Road, Kishanganj, Bihar; ${ }^{5}$ Post Graduate Trainee, Department of Obstetrics \& Gynaecology, Mata Gujri Memorial Medical \\ College \& LSK Hospital, Purabbali, Dinajpur Road, Kishanganj, Bihar, India
}

Corresponding author: Dr Mihir Kumar Jha, Associate Professor, Department of Radiodiagnosis, Shri Ramkrishna Institute of Medical Sciences and Sanaka Hospital, Malandighi, Kanksha, Durgapur, West Bengal, India

DOI: http://dx.doi.org/10.21276/ijcmsr.2019.4.2.22

How to cite this article: Subrat Prasad, Mihir Kumar Jha, Shalini Sahu, Ichchhit Bharat, Chandni Sehgal. Evaluation of ovarian masses by color doppler imaging and histopathological correlation. International Journal of Contemporary Medicine Surgery and Radiology. 2019;4(2):B95-B101.

\section{A B S T R A C T}

Introduction: Adnexal masses pose a special diagnostic challenge and suspicion for malignancy is based largely on imaging appearance. As a primary imaging modality, ultrasonography (US) can provide diagnostic information for evaluating ovarian masses. This study had revealed the change of spectral Doppler wave form characteristics (resistive index, pulsatility index) of ovarian masses and differentiates them into benign and malignant lesions and correlate with histopathological findings. Material and Methods: Thirty nine women who were referred to the radiology department for abdomen or pelvis USG from Gynaecology OPD at a tertiary care hospital, Kishanganj, Bihar with a clinical diagnosis of adenexal mass by per abdomen or per vaginal examination or history of irregular lower abdominal pain or bleeding disorder were included in the study. Transabdominal USG with Doppler study was performed in all cases. On spectral Doppler, the lowest resistance index (RI), and maximum peak systolic velocity (PSV) detected at any point in the mass was used for analysis. After USG patients were planned for surgery. Accordingly then post operated excised tumor were send for histopathology. Thus this study was a correlation of USG finding (including grey scale and Doppler) in cases of ovarian/adenexal masses considering with histopathology as a gold standard.

Results: Different variables on USG and CDUS were used in diagnosis of benign and malignant ovarian tumors in 39 patients. A total of 56 masses detected in right and left adenexa. Excellent agreement between histopathology and USG (grey scale and CDUS) was found for the diagnosis of benign and malignant tumor of ovary. CDUS shows RI value ranges from 0.4 to 0.9 are malignant and PI value ranges from 0.48 to 1.33 which is comparable with literature. Grey scale USG shows necrosis and calcification present in all malignant cases proved histopathologically. Among 39 patients 13 shows flow within the tumor, but only 4 of them which were proved by histopathology as malignant ranges from 0.4-0.9. however 6 of them shows value ranges from 0.8-0.9 (borderline) but they were proved as benign by histopathology and USG sensitivity found to be $100 \%$, specificity $80 \%$, PPV $36 \%$ and NPV $100 \%$.

Conclusion: Multiparameter analysis utilizing B-mode USG along with Color Doppler and Spectral Doppler is the mainstay in diagnosis of patients with ovarian tumors.

Keywords: Ovarian Mass, Ultrasonography, Color Doppler, Malignancy

\section{INTRODUCTION}

Ovarian mass represents a common problem in clinical practice. Of all gynecologic carcinoma, ovarian carcinoma represents the greatest clinical challenge. The majority of ovarian mass are benign (80\%) with cystic, solid, and mixed characteristics and a favorable diagnosis. The other 20\% masses are malignant, so we need diagnostic means which permit accurate classification of ovarian masses before surgery. ${ }^{1}$ Ultrasonography is considered the primary imaging modality for confirmation of the ovarian origin of mass and characterization of nature of mass as benign or malignant. ${ }^{2}$ It correlates morphologic images with gross macroscopic pathologic features of ovarian masses. However, when morphologic features alone are applied to the prediction of ovarian malignancy, there is tendency to over diagnose malignant tumors because of a substantial overlap between malignant and benign masses. Therefore, addition of color Doppler imaging with pulsed Doppler spectral analysis improves the characterization of ovarian masses by means 
of quantitative blood flow measurements obtained from tumor vessels and so increases sensitivity and specificity of characterization of ovarian masses. ${ }^{3}$ High operator dependence and extreme variability of characteristics of ovarian tumor make a precise diagnosis still difficult. ${ }^{4,5}$

Determination of a degree of suspicion for malignancy in an adnexal mass is the most critical step after identification of the mass. Many different scoring systems exist for discriminating benign from malignant adnexal masses. These scoring systems evaluate masses for solid elements, cyst wall thickness, number, thickness, and irregularity of septations, and the presence of ascitic fluid. Numerical scores are applied and masses that score higher than a certain cutoff are considered potentially malignant. ${ }^{6}$

In order to ensure the availability of explicit criteria for predicting the nature of ovarian tumors, of late, a number of scoring systems have been proposed by using variables such as the presence of nodularity, solid areas, internal echoes, septae, necrosis, calcification and irregularity of borders. ${ }^{7}$ Ovaries are sonographically hypoechoiec compared with surrounding structures. Many morphological scoring systems on USG have been proposed, based on the wall thickness inner wall structure, septal characteristic, and echogenecity of the lesion. CDUS of ovarian masses helps in differentiating benign and malignant tumor. ${ }^{8}$ It is also used in conjunction with pulsed CDUS to identify vessels for waveform analysis. Two indices have been used in analyzing Doppler waveforms: the PI and the RI. RI less than 0.4-0.8 and PI less than 1.0 are generally considered to be suspicious for malignancy. ${ }^{9}$ Benign lesions tend to initiate new tumor blood vessel formation peripherally from pre-existing host vessels; whereas malignant tumors tend to initiate new tumor blood vessel formation centrally. The newly formed tumor vessels have a deficiency of smooth muscle in their walls as opposed to their calibre. Due to muscular paucity, these vessels present a low resistance to the blood flow and thereby receive a large volume flow than normal vessels, which have high impedence. Some differentiation between benign and malignant masses is achieved by quantifying this differences. ${ }^{10}$

This study had revealed the change of spectral Doppler wave form characteristics (resistive index, pulsatility index) of ovarian masses and differentiates them into benign and malignant lesions and correlate with histopathological findings.

\section{MATERIAL AND METHODS}

The study sample comprised of 39 patients having clinically suspected ovarian masses on the basis of a positive history and clinical examination. USG was performed on sonoline G 50 and versa pro machine with $3.5-5.5 \mathrm{MHz}$ transabdominal probe. TVS was performed whenever required to obtain additional findings. For transabdominal USG patient was advised to hold urine and examination was performed in supine position. Scanning of lower abdomen and pelvic region was done in different planes using 3.5-5.5 $\mathrm{MHz}$ curvilinear transducer.

The presence of a mass was first confirmed on gray scale all masses were awarded morphologic scores as per the Sassone's scoring system. The scores could range from a minimum of 4 to maximum 15 points. Following gray scale scanning, color flow signals were superimposed in real time and the regions of intratumoral neovascularisation were identified as the areas of color. A cursor was placed at the region of interest and the spectral wave forms were obtained from which the pulsatility and resistive indices were noted (PI and RI). A mass was declared as not to be having a detectable blood flow, in case we failed to obtain color flow signals after 25 minutes of continuous scanning. In such cases, using maximum magnification, the sampling box was moved all over the tumor area, so as to identify any possible areas of color. All the patients underwent surgical exploration and the post surgical histopathology findings were correlated with the morphologic scorings and Doppler indices RI/PI value that had been obtained preoperatively.

\begin{tabular}{|l|c|c|}
\hline Menstrual status & Benign & Malignant \\
\hline Premeanrche & - & - \\
\hline Premenopausal & 24 & 2 \\
\hline Postmenopausal & 11 & 2 \\
\hline Total & $35(89.7 \%)$ & $4(10.3 \%)$ \\
\hline
\end{tabular}

Table-1: Comparison of menstrual status with histopathological findings

\begin{tabular}{|l|c|c|}
\hline Type of tumor & No. & Percentage \\
\hline Mature cystic teratoma & 12 & $30.8 \%$ \\
\hline Mucinous cystadenoma & 6 & $15.5 \%$ \\
\hline Simple cyst & 5 & $13 \%$ \\
\hline Cystic teratoma & 9 & $23.4 \%$ \\
\hline Serous cystadenoma & 2 & $5.2 \%$ \\
\hline Corpus lutel cyst & 1 & $2.6 \%$ \\
\hline Choriocarcinoma & 4 & $10.4 \%$ \\
\hline
\end{tabular}

Table-2: Type of tumor detected in 39 women by histopathological finding

\begin{tabular}{|l|c|}
\hline Name of the Tumor & Score \\
\hline Choriocarcinoma & $13-14$ \\
\hline Mucinous cystadenoma & $10-12$ \\
\hline Mature cystic teratoma & 12 \\
\hline Cystic teratoma & 7 \\
\hline Serous cystadenoma & 8 \\
\hline Corpous luteal cyst & 8 \\
\hline Simple cyst & 7 \\
\hline Thecaluteal cyst & $7-8$ \\
\hline Mature teratoma (dermoid) & 8 \\
\hline Fluid filled cystic lesion & 6 \\
\hline Unilocated epithelial lining cyst & 6 \\
\hline Physiological/infective cyst & 5 (normal) \\
\hline \multicolumn{2}{|c|}{ Table-3: USG evaluation by grey scale score } \\
\hline
\end{tabular}

\begin{tabular}{|c|c|c|}
\hline \multicolumn{2}{|c|}{ Flow [Positve] } & Flow [Negative] \\
\hline Benign & Malignant & \\
\hline 9 & 4 & 26 \\
\hline \multicolumn{2}{|c|}{$13(33.33 \%)$} & $26(66.6 \%)$ \\
\hline \multicolumn{2}{|c|}{ Table-4: Doppler study for color flow within the tumor } \\
\hline
\end{tabular}




\begin{tabular}{|l|c|c|}
\hline Serial No. & Right & Left \\
\hline 1 & - & 1.74 \\
\hline 2 & - & 2.55 \\
\hline 3 & - & 3.08 \\
\hline 4 & - & 1.3 \\
\hline 5 & 0.48 & - \\
\hline 6 & 0.61 & - \\
\hline 7 & 1.33 & - \\
\hline 8 & 0.99 & - \\
\hline 9 & 4.1 & - \\
\hline 10 & 3.35 & - \\
\hline 11 & 3.0 & - \\
\hline 12 & 7.4 & - \\
\hline 13 & 1.83 & - \\
\hline \multicolumn{2}{|c|}{ Table-5: Range of pulsatility index } \\
\hline
\end{tabular}

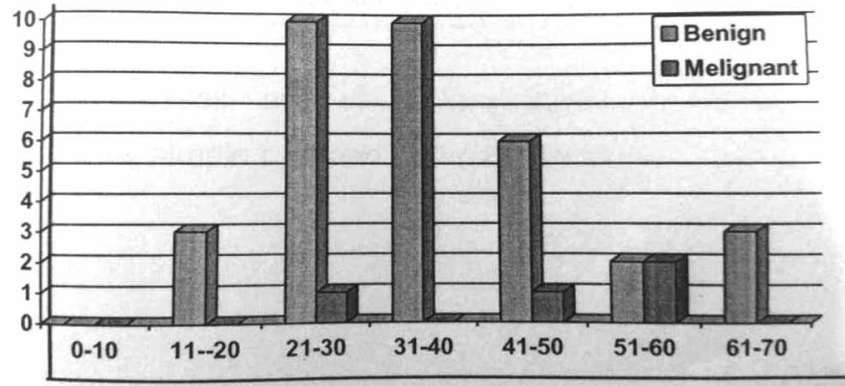

Figure-1: Distribution of cases in different age groups

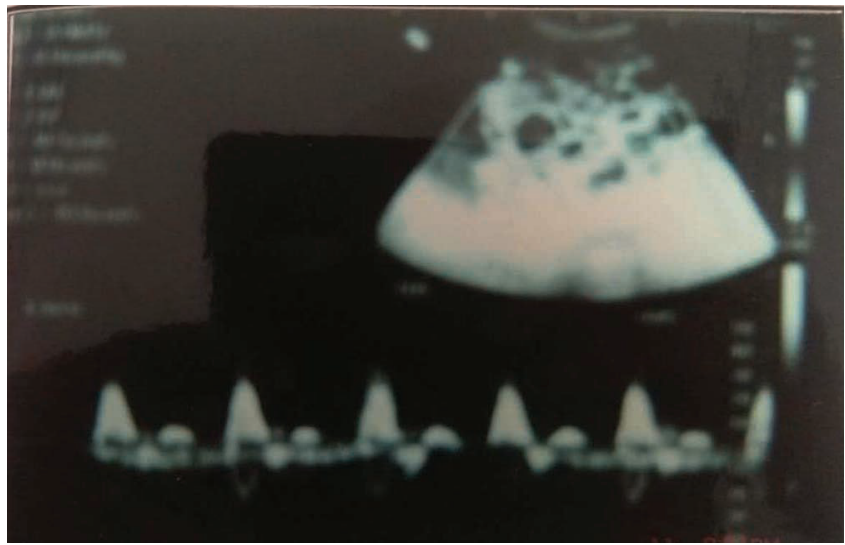

Figure-1: USG showing Doppler spectral tracing from intratumoral vessel

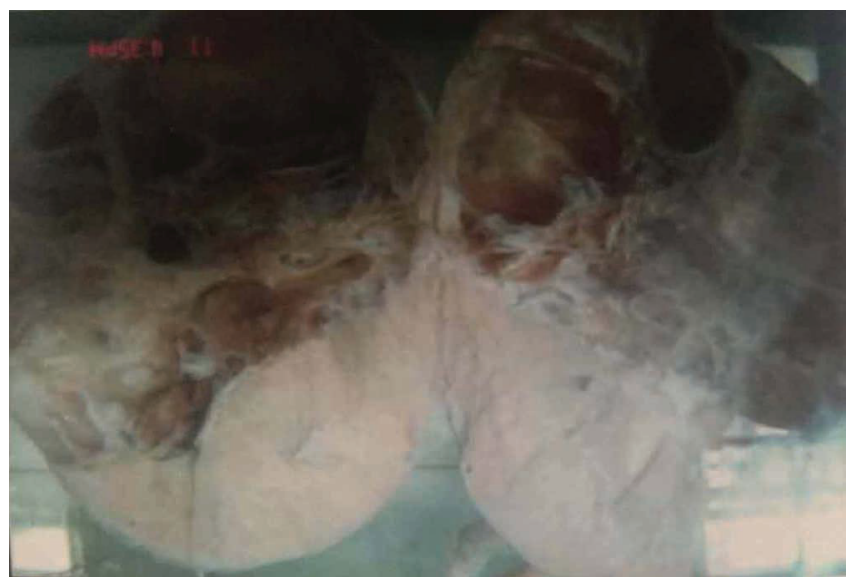

Figure-2: Postoperative specimen of solid mature cystic teratoma

\begin{tabular}{|l|c|}
\hline Calcification- Rt & Calcification- Lt \\
\hline 4 (Positive) & 3 (Positive) \\
\hline 35 (Negative) & 14 (Negative) \\
\hline 39 (Total) & 17 (Total) \\
\hline Necrosis- Rt & Necrosis-Lt \\
\hline 11 (Positive) & 4 (Positive) \\
\hline 28 (Negative) & 13 (Negative) \\
\hline 39 (Total) & 17 (Total) \\
\hline \multicolumn{2}{|c|}{ Table-7: Calcification and necrosis (by USG) within the tumor } \\
\hline
\end{tabular}

\begin{tabular}{|c|c|c|c|c|}
\hline & \multicolumn{3}{|c|}{ Histopathological findings } & \multirow[t]{2}{*}{ Total } \\
\hline & Yes & \multicolumn{2}{|c|}{ No } & \\
\hline USG (Benign) & 0 & \multicolumn{2}{|c|}{35} & 35 \\
\hline USG (Malignant) & 4 & \multicolumn{2}{|r|}{0} & 4 \\
\hline Total & \multirow{2}{*}{\multicolumn{2}{|c|}{4}} & 35 & 39 \\
\hline \multicolumn{3}{|l|}{ Summetric Measures } & & \\
\hline & Value & Asmp. Std. Error & Approx. T & Approx. Sig. \\
\hline Measure of agreement Kappa & 1.000 & 0.000 & 6.245 & 0.000 \\
\hline $\mathrm{N}$ of valid cases & 39 & & & \\
\hline \multicolumn{5}{|c|}{$\begin{array}{l}\text { a. Not assuming the null hypothesis; b. Using the asymptotic standard error assuming the null hypothesis } \\
\text { According to Cohen's Kappa when both variables have the same number of categories of a value of } 1 \text { indicates prefect agreement } \\
\text { between two departments }\end{array}$} \\
\hline
\end{tabular}




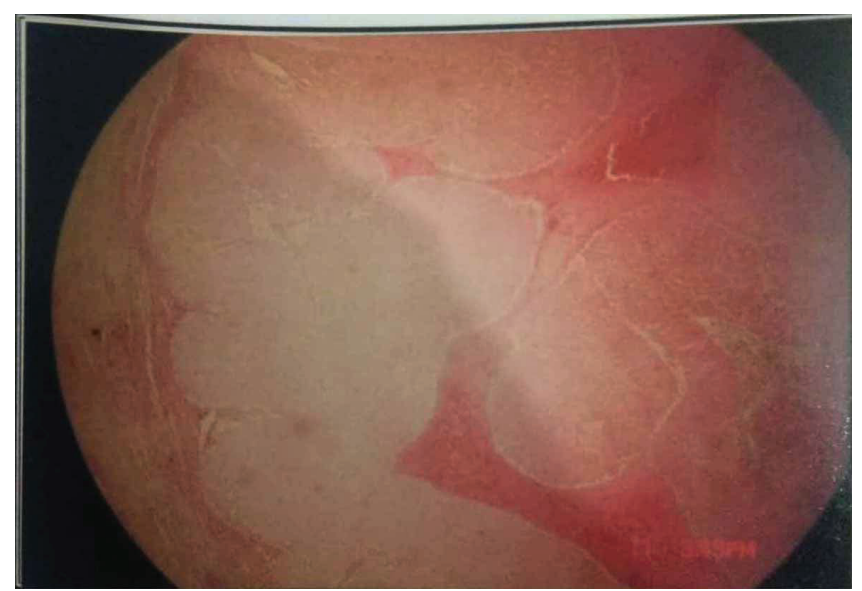

Figure-3: Histopathological slide of haemorrhagic corpus luteal cyst

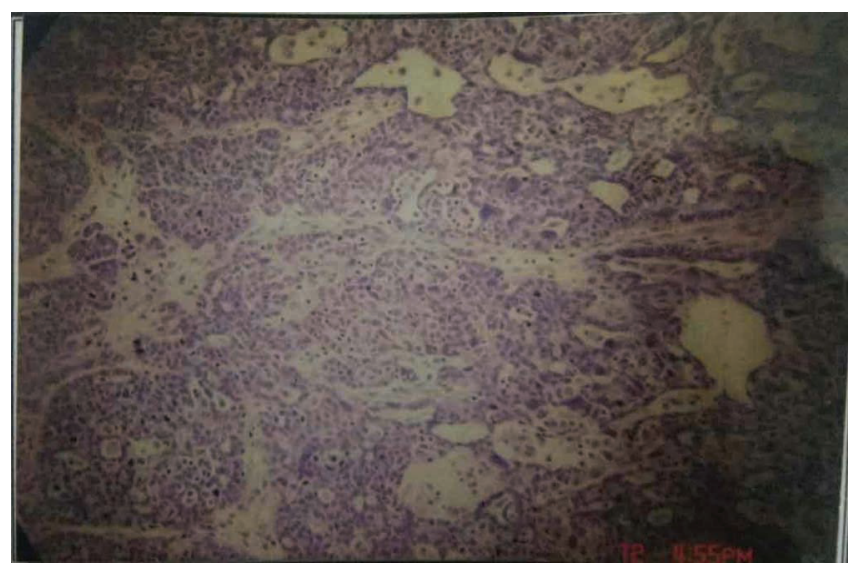

Figure:4- Histopathological slide of sertoli leydig cell tumor (showing tubular

\section{RESULTS}

Thirty nine women suspected of having ovarian mass referred from Department of Gynaecology over the period of $16^{\text {th }}$ month [Feb 2015 to June 2016], were included in the study subjected for pelvis USG after obtaining detail clinical history as per proforma post operative histopathological reports were obtained. A total of 56 masses were detected in 39 patients. On histopathological examination, 4 masses proved to be malignant and 24 masses were benign and rest were physiological cyst/ infective process, which showed only cyst increase in size on follow up USG and these masses were not operated and managed conservatively. Hence they were not included in our analysis. Morphological scores were assigned to all masses. Doppler blood flow could not be identified in 26 patients. In the remaining 13 patients in whom blood flow was obtained, pulsatility and resistance indices were calculated and correlated with their histopathologic results. Among them 9 in which intra tumoral flow noted the Doppler RI and PI values showed nature of masses condition. Among the study participants $89.7 \%$ were having benign lesions and rest $10.3 \%$ were having malignant lesions [Table 1]. Majority of cases are of mature cystic teratoma, mucinous cystadenoma, simple cyst and cystic teratoma [Table 2, Fig. $2,3]$. Grey scale/morphological score show maximum value of 14 for malignant lesion for benign one value ranges from
6-12 [Table 3]. About 13 masses in which intratumoral flow [Fig.1] was present and among them 9 were benign and 4 were malignant [Table 4].

Among 39 patients 13 shows flow within the tumor, but only 5 of them shows PI value ranging from $0.48-1.33$ and by histopathological correlation they were found as malignant with sensitivity $100 \%$, specificity $97 \%$, PPV $80 \%$ and NPV 100\% [Table 5].

Among 39 patients 13 shows flow within the tumor, but only 4 of them which were proved by histopathology as malignant ranges from $0.4-0.9$. however 6 of them shows value ranges from 0.8-0.9 (borderline) but they were proved as benign by histopathology and USG sensitivity found to be $100 \%$, specificity 80\%, PPV 36\% and NPV 100\% [Table 6].

All the cases which were proven as malignant by histopathology contain necrosis and calcification in USG (grey scale) [Table 7, Fig.4].

\section{DISCUSSION}

USG finding of different tumors on gray scale CDUS

Choriocarcinoma of ovary showed heterogenous echotexture with irregular or lobulated margin. Areas of necrosis and calcification noted within the lesion. ${ }^{12}$ Doppler study showed intratumoral blood flow with low RI/PI values. Serous cystadenoma showed heterogenous echotexture with septation and clacification noted within the lesion. Some of them showed necrotic areas, with intratumoral blood flow but high RI/PI values. Mucinous cystadenoma showed thick walled heterogenous echotexture with multiple varying sizes cystic areas and septation having solid component with blood flow showed high RI/PI values. Mature teratoma showed hetergenous echotexture with solid and cystic areas. Some solid component noted within the tumor. Cystic teratoma showed low level echogenic fluid filled cystic tumor with no internal Doppler flow noted..$^{13,14}$

On color flow imaging we failed to obtain color signals in 26 patients. However, no malignancy was encountered in this group. Blood flow was obtained in all the 4 malignant masses and 9 benign masses. Analysis of color flow data as a predictor of malignancy, we obtained a sensitivity of $100 \%$ and NPV of $100 \%$ while specificity and PPV were $80 \%$ and $36 \%$ respectively.

The range of values of PI for malignant masses was 0.48 to 1.33 with a mean of 0.85 . PI of benign masses ranged from 1.3 to 7.4 with mean standing at 3.15 , by using a PI value of 1.1 as the cut-off point, for differentiating benign and malignant lesions. Decreasing the cut off value to 1 or 0.9 would make the test less sensitive but more specific. The range of values of $\mathrm{RI}$ for malignant masses was 0.4 to 0.98 with a mean of 0.5 . RI of benign masses ranged from 0.4 to 0.9 with mean standing at 1.05 , using an $\mathrm{RI}$ value of 0.6 as the cut-off point. Decreasing the cut-off value to 0.5 or 0.4 would make the test less sensitive but more specific. There is a wide variation of results in the works of below mentioned authors with the proposed cut-off values of RI ranging from 0.41 to 0.8 . Our results fall within the spectrum of above mentioned studies. Various authors have documented spectrum of USG (grey scale/Doppler study) for evaluation of ovarian masses. Karimi-Zarchi M et al (2016) ${ }^{15}$ proved 
that four criteria could be combined in malignancy score which was calculated as product of serum CA 125 presence of serum, RI $(\mathrm{RI}<0=0.5)$, PSV (PSV> or $=40 \mathrm{~cm})$. They conducted the sensitivity was $98 \%$ and specificity was $85 \%$, PPV was $87.5 \%$ and NPV $97.6 \%$. In the present study mean value of $\mathrm{RI}$ in malignant lesion is approx 0.5 , with sensitivity 100\%, specificity 80\%, PPV 36\% and NPV 100\%. Our result fall within the spectrum of above mentioned studies. Valentin L et al proved small proportion of solid issue with papillary projection and intratumoral flow suggest malignant tumor. ${ }^{5}$ Brown et al in their study concluded that grey scale and CDUS finding and solid component within the most statistically significant predictor of ovarian malignancy. ${ }^{16}$

Tailor A et al took age, tumor diameter, volume, papillary projection, PSV, time as variables and averaged maximum velocity RI and PI. ${ }^{17}$ They included the variables for each patient: (1) age, (2) maximum tumor diameter, (3) tumor volume, (4) unilocularity (presence (0) or absence(1)), (5) papillary projections (presence (1) or absence $(0)),(6)$ random echogenicity (presence (1) or absence (0)), (7) highest peak systolic velocity (PSV), (8) time-averaged maximum velocity (TAMXV), (9) pulsatility index (PI) and (10) resistance index (RI) for predicting the presence or absence of malignancy. The accuracy of this prediction appears to be better than that of morphological or Doppler criteria when the later is used independently. Tailor A et al in their study found complex structures and echogenic lesions were found in ovarian tumor of low malignant potential and malignant tumor than in the cysadenomas and the difference was statistically significant. RI value in this study had showed $(0.48+1-0.07) .{ }^{17}$

Alcazar JC et al studied in ovarian cancer by TVS and CDUS. They concluded that purely solid tumor indicates probability of metastatic carcinoma. ${ }^{18}$ However variables such as bilaterality, volume, ecogenecity, speta, papillary projection, soild areas, Doppler indices RI/PI do not show statistical difference. Varras $\mathrm{M}$ et al in their study showed the limitations of USG in early detection of ovarian cancer and Doppler USG is not an independent indicator for malignancy. Consistent with the findings of other studies. ${ }^{19}$ Consistent with the findings of other studies our result also showed necrosis, solid component and calcification on USG to be features suggesting malignant lesion. However Doppler evaluation helps to confirm the diagnosis.

Szpurek D et al $(2006)^{20}$ studied ovarian fibrosarcoma by CDUS (variables were RI/PI and PSV). They concluded low vascular resistance can be encountered in ovarian fibrosarcoma and intratumoral Doppler wave form might help in prediction of rare malignant tumors. Gramellini et al showed central Doppler flow was the only significant parameter among those analyzed using Color Doppler which was useful for the diagnosis of a malignant neoplasm with a diagnostic accuracy of $82.95 \%$ sensitivity $55.55 \%$ but low false positive $7.95 \%{ }^{21}$ Alcazar JL et al studied on adenexal malignancy by USG and color Doppler and histopathological correlation. They concluded sensitivity, specificity, PPV, NPV were 85.7\%, 100\%, 1005 and 95.4\% respectively. Overall accuracy of USG with CDUS was $96.4 \% .{ }^{22}$ Marret $\mathrm{H}$ et al analyzed and established that USG is the gold standard for ovarian cyst diagnosis. They found papillary formations and masses with a nonhyperechoic solid component are the most statistically significant predicators of malignant ovarian mass. ${ }^{23}$ They concluded that DUS and morphologic parameters have a sensitivity of $80 \%$ and specificity of $93 \%$ that make test as the gold standard for ovarian masses diagnosis. Guerriero $S$ et al studied comparison of conventional color DUS and power Doppler imaging for the diagnosis of ovarian cancer. Using both modalities of color Doppler or was at least one of the two Doppler techniques should be used in conjunction with $\mathrm{B}$-mode imaging in order to diagnose malignant lesion. ${ }^{24}$ Sawicki $W$ et $\mathrm{al}^{11}$ proved their study that Doppler flow within the tumor was $74.5 \%$ in benign and $98.6 \%$ in malignant masses $(\mathrm{P}<0.0001)$. Average value in an echogenic portion defined as malignant by B-mode. They found peripheral vasculature in benign on the other hand, central and peripheral and mixed in malignant and location and intensification of vascularisation in examined masses which permit the differentiation of malignant and benign lesions. Consistence with the finding of others; this study also proved that low vascular resistance and intratumoral flow signify malignant tumor with a diagnostic accuracy of $80 \%$ and sensitivity of $100 \%$.

Pascual MA et al analysed grayscale and color Doppler USG feature with histopathological correlation. ${ }^{25}$ They concluded when a ovarian cystic mass with papillae, necrosis with Doppler values of low RI value within the mass suggests malignancy. Smolen et al included six variables age, bilaterility, septae, necrosis, volume and color score (RI/PI) in their study. Results were sensitivity $74.6 \%$ and specificity $94.7 \%$. For ovarian mass our study showed sensitivity $100 \%$ and specificity $80 \%$. That falls within the spectrum of aforementioned study. Varras $\mathrm{M}$ et al proved CDUS imaging is very useful in detecting of uterine adnexal malignancy because of revascularization in malignant tumors. Presence of septum, pappilary projections, or solid components present within the lesion supports in favour of malignancy. ${ }^{19}$

Cohen L et al studied in ovarian cancer by using USG and proved that TVS in expert hand is sensitive but not specific for discriminating benign from malignant but judicious use of color Doppler evaluation may help to discriminate benign and malignant lesion. ${ }^{26}$ Czekierdowski $\mathrm{A}$ et al studied color Doppler blood flow measurements and microvessel density assessment in ovarian tumors. Finally they came to a conclusion that low resistance to blood flow as measured by the RI or PI on CDUS may by positively correlate with the micro vessel density in the malignant ovarian tumors. ${ }^{27}$ Valentin L et al came in a conclusion that CDUS examination is helpful only in differentiating multilocular cysts with solid parts. Thus greater the solid parts in multilocular cyst, greater the potential of the Doppler examination to improve diagnostic accuracy. ${ }^{28}$ Caruso $\mathrm{A}$ et al proved usefulness of color Doppler in the differential diagnosis of adenexal masses. ${ }^{29}$ Doppler analysis (vascular score) was compared to that of some morphological scores. The sensitivity was $100 \%$ for all the technique used. But Doppler analysis had a higher specificity. Finally they came in a conclusion that color CDUS of ovarian tumors seem to be a reliable method in the differential diagnosis of adnexal masses. Our 
study also proved that Doppler evaluation (RI/PI) indices has important role to discriminate benign from malignant ovarian tumor.

Shah D et al $(2012)^{30}$ concluded that PI was lesser in malignant lesion then in benign lesions $(<$ or $=1.0)$. However the PI value sometimes showed considerable overlap between benign and malignant lesions indicating that CDUS has limitations in the differentiation of benign form malignant ovarian masses. Salem $\mathrm{S}$ et al came in a conclusion that their results showed a high positive predictive value of high impedence flow in benign adnexal disease and a predominance of low impedance flow in malignant adnexal disease. However, the PI showed considerable overlap between benign and malignat lesions, indicating that DUS has severe limitations in the differentiation of benign from malignant adnexal diasese on the basis of low impedance flow $(\mathrm{PI}<1.0)$. But in our study only cases showed overlap in PI value for malignant lesion. However our result fall within the spectrum of proved PI value by different authors; such as value of PI $(<\mathrm{OR}=1)$ for malignant lesion.

The comparison of USG findings with that of histopathology shows good correlation in diagnosing benign and malignant ovarian mass. In overall transabdominal USG with Doppler study is fairly accurate in diagnosing benign and malignant ovarian tumor.

Madan R, et al $2004^{31}$ showed that the sonomorphologic evaluation following Sassone scoring system had a sensitivity of $92.3 \%$, specificity $55.3 \%$, PPV $54.3 \%$, NPV $92.8 \%$ and a diagnostic accuracy of $68.9 \%$ ). Forty six out of 74 masses were considered suspicious of malignancy (Sassone score $=9$ ) of which 25 were malignant and 21 were benign. High scoring (= 9) benign lesions were inflammatory adnexal masses, endometriomas, cystic teratomas, mucinous cystadenomas, and thecoma. Non-suspicious sonomorphology (score<9) was noted in 28 mass lesions- 26 were benign and 2 were malignant (1 immature teratoma and 1 serous cystadenocarcinoma). ${ }^{31}$ Color flow was detected in 77.02\% masses- - 92.5\% (25/27 masses) malignant masses were vascularised as compared to $68.08 \%$ (32/47 masses) benign adnexal masses; increased flow was noted in $92 \%$ malignant lesions and only $21.87 \%$ benign masses ( 5 inflammatory masses, one broad ligament fibroid and one thecoma). On pulsed Doppler, the average value of RI in malignant ovarian neoplasms amounted to $0.40 \pm 0.15$ and was higher in benign masses [0.51 \pm 0.11$]$. The mean PI of $0.61 \pm 0.19$ in malignant adnexal masses was lower than $0.89 \pm 0.32$ in benign lesions. The mean PSV in benign masses $(12.74 \pm 8.4 \mathrm{~cm} / \mathrm{sec})$ was lower than that in malignant adnexal masses $(23.92 \pm 13.6 \mathrm{~cm} / \mathrm{sec})$. The mean vascular score (Caruso et al) was higher in malignant ovarian neoplasms $(7.64 \pm 2.64)$ as compared to benign lesions $(2.34$ $\pm 2.23) .^{31}$

There is considerable overlap in the morphologic patterns of various ovarian masses. Gray scale ultrasonography in combination with color Doppler, spectral Doppler, and their combination in the form of scoring systems like ALCAZAR is proposed as the foremost diagnostic modality in patients with ovarian tumor, so as to establish the definite diagnosis of malignancy early in the course of the disease. ${ }^{32}$

\section{CONCLUSION}

The present study evaluates ovarian mass by USG and CDUS considering histopathological examination of post operative specimen as gold standard. The purpose of this work was to study the morphological characteristic of ovarian masses by USG and change of spectral Doppler wave form characteristic (RI/PI) of ovarian masses and differentiate them in to benign and malignant lesions with a correlation of histopathological finding. The morphologic scores of benign masses are comparatively lower than that of malignant masses. A mass showing absence of color flow signals on color Doppler is more likely to be benign, though reverse is not true. Low resistance to blood flow with low pulsatility and resistive indices is a feature of malignant masses. High resistance blood flow with high PI and RI values is suggestive of benign masses. An area of overlap exists between the range of values of benign and malignant masses with both on morphologic as well as haemodynamic assessment. In the overall scenario, pulsatility index is more accurate followed by resistive index and then by morphologic scores in predicting the nature of a mass. The limitations of our study were the small sample size and the inability to compare our values in the large scale. Determination of a degree of suspicion for malignancy in an adnexal mass is the most critical step after identification of the mass and has a profound effect on patient survival. Color flow imaging and spectral Doppler have a promising role in the evaluation of adnexal masses. Morphologic analysis of adnexal masses is done to classify them as either low risk or high risk. The most ominous features are non-fatty solid vascularised tissue identified by Color Doppler US. Spectral Doppler waveform characteristics- RI, PI and PSV correlate well with malignancy and are based on the fact that tumor vessels are morphologically abnormal.

\section{REFEENCES}

1. Desai D, Desai VA, Verma RN, Shrivastava A. Role of gray scale and color Doppler in differentiating benign from malignant ovarian masses. J Midlife Health. 2010;1(1):23-25.

2. Jeong YY, Outwater EK, Kang HK. Imaging evaluation of ovarian masses. Radiographics. 2000;20(2):1445-70.

3. DePriest PD, Shenson D, Fried A, Hunter JE, Andrews SJ, Gallion $\mathrm{HH}$, et al. Amorphology index based on sonographic findings in ovarian cancer. Gynecol Oncol. 1993; 51(3):7-11.

4. Timmerman D, Schwarzler P, Collins WP, Claerhout F, Coenen M, Amant F, et al. Subjective assessment of adnexal masses with the use of ultrasonography: an analysis of inter-observer variability and experience. Ultrasound Obstet Gynecol 1999; 13 (5):11-16.

5. Valentin L. Pattern recognition of pelvic masses by gray-scale ultrasound imaging: the contribution of Doppler ultrasound. Ultrasound Obstet Gynecol 1999; 14 (1):338-347.

6. Sassone AM, Timor-Tritsch IE, Artner A, et al. Transvaginal sonographic characterization of ovarian disease: Evaluation of a new scoring system to predict malignancy. Obstet Gynecol 1991; 78 (5): 70.

7. Lerner JP, Timor-Tritsch IE, Federman A, et al. 
Transvaginal ultrasonographic characterization of ovarian masses with an improved, weighted score. Am J Obstet Gynecol 1994; 170 (6): 81.

8. Sayasneh A, Ekechi C, Ferrara L, et al. The characteristic ultrasound features of specific types of ovarian pathology (review). Int J Oncol. 2014;46(2):445-458.

9. Jung SI. Ultrasonography of ovarian masses using a pattern recognition approach. Ultrasonography. 2015;34(3):173-182.

10. Shah D, Shah S, Parikh J, Bhatt CJ, Vaishnav K, Bala DV. Doppler ultrasound: a good and reliable predictor of ovarian malignancy. J Obstet Gynaecol India. 2012;63(3):186-189.

11. Sawicki W, Spiewankiewicz B, Cendrowski K, et al. Studied to evaluate preoperative discrimination between malignant and benign adnexal masses with TVS and color blood flow imaging. Clin Exp Obstet Gynecol 2004; 31(2):85-98.

12. Mascilini F, Moro F, Di Grazia FM, Leombroni M, Distefano MG, Fanfani F. Clinical and ultrasound features of non-gestational ovarian choriocarcinoma. Ultrasound Obstet Gynecol. 2018;52(1):121-123.

13. Wasnik AP, Menias CO, Platt JF, Lalchandani UR, Bedi DG, Elsayes KM. Multimodality imaging of ovarian cystic lesions: Review with an imaging based algorithmic approach. World J Radiol. 2013;5(3):113125.

14. Wang Q, Guo C, Zou L, et al. Clinicopathological analysis of non-gestational ovarian choriocarcinoma: Report of two cases and review of the literature. Oncol Lett. 2016;11(4):2599-2604.

15. Karimi-Zarchi M, Dehshiri-Zadeh N, Sekhavat L, Nosouhi F. Correlation of CA-125 serum level and clinico-pathological characteristic of patients with endometriosis. Int $\mathrm{J}$ Reprod Biomed (Yazd). 2016;14(11):713-718.

16. Brown DL, Doubilet PM, Miller FH, et al. Benign and malignant ovarian masses: selection of the most discriminating gray-scale and Doppler sonographic features. Radiology 1998; 208 (1):103-110.

17. Tailor A, Jurkovic D, Bourne TH, Collins WP, Campbell S. Sonographic prediction of malignancy in adnexal masses using multivariate logistic regression analysis. Ultrasound Obstet Gynecol. 1997;10(1):41-7.

18. Guerriero S, Alcazar JL, Pascual MA, Ajossa S, Olartecoechea B, Hereter L. Preoperative diagnosis of metastatic ovarian cancer is related to origin of primary tumor. Ultrasound Obstet Gynecol. 2012;39(5):581-6.

19. Varras M. Benefits and limitations of ultrasonographic evaluation of uterine adnexal lesions in early detection of ovarian cancer. Clin Exp Obstet Gynecol. 2004;31(2):85-98.

20. Szpurek D, Moszyński R, Englert-Golon M, Pawlak M, Sajdak S. Clinical value estimation of the Doppler indicies: PI, RI and PSV, TAMXV and MEDV in early differentiation of the ovarian tumors malignancy. Ginekol Pol. 2006;77(8):597-602.

21. Gramellini D1, Rutolo S, Verrotti C, Piantelli G, Fieni S, Vadora E. Sonographic characterization, Doppler ultrasonography and tumor markers in the diagnosis of malignancy of ovarian masses. Minerva Ginecol.
2001;53(1):1-11.

22. Alcázar JL, Errasti T, Zornoza A, Mínguez JA, Galán MJ. Transvaginal color Doppler ultrasonography and CA-125 in suspicious adnexal masses. Int J Gynaecol Obstet. 1999;66(3):255-61.

23. Marret H. Doppler ultrasonography in the diagnosis of ovarian cysts: indications, pertinence and diagnostic criteria.J Gynecol Obstet Biol Reprod (Paris). 2001;30(1 Suppl):S20-33.

24. Guerriero S, Alcazar JL, Ajossa S, Lai MP, Errasti T, Mallarini G, Melis GB. Comparison of conventional color Doppler imaging and power doppler imaging for the diagnosis of ovarian cancer: results of a European study. Gynecol Oncol. 2001; 83(2):299-304.

25. Pascual MA, Tresserra F, López-Marín L, (2000). Role of color Doppler ultrasonography in the diagnosis of endometriotic cyst. J Ultrasound Med, 19, 695-9.

26. Cohen L, Fishman DA. Ultrasound and ovarian cancer. Cancer Treat Res. 2002;107(4):119-32.

27. Czekierdowski A, Szymański M, Szumiło J, Kotarski J. Color Doppler blood flow measurements and microvessel density assessment in ovarian tumors. Ginekol Pol. 2003;74(9):695-700.

28. Valentin L, Ameye L, Savelli L, Fruscio R, Leone FP, Czekierdowski A. Unilocular adnexal cysts with papillary projections but no other solid components: is there a diagnostic method that can classify them reliably as benign or malignant before surgery? Ultrasound Obstet Gynecol. 2013;41(5):570-81.

29. Caruso A, Caforio L, Testa AC, Ciampelli M, Panici PB, Mancuso S. Transvaginal color Doppler ultrasonography in the presurgical characterization of adnexal masses. Gynecol Oncol 1996; 63(6):184-191.

30. Shah D, Shah S, Parikh J, Bhatt CJ, Vaishnav K, Bala DV. Doppler ultrasound: a good and reliable predictor of ovarian malignancy. J Obstet Gynaecol India. 2012;63(3):186-189.

31. Madan R, Narula M K, Chitra R, Bajaj P. Sonomorphological and color doppler flow imaging evaluation of adnexal masses. Indian J Radiol Imaging 2004;14(5):365-72.

32. DePriest PD, Shenson D, Fried A, Hunter JE, Andrews SJ, Gallion $\mathrm{HH}$, et al. Amorphology index based on sonographic findings in ovarian cancer. Gynecol Oncol. 1993;51(3):7-11.

\section{Source of Support: Nil; Conflict of Interest: None}

Submitted: 20-04-2019; Accepted: 11-05-2019; Published online: 03-06-2019 